\title{
La protección del consumidor sobreendedeudado e insolvente en los Estados Unidos de América
}

\author{
Dr. Julio Álvarez Rubio \\ Universidad de Cantabria
}

Sumario: I. Consideraciones previas. II. La nueva regulación. Planteamiento general. 2.1. Una nueva perspectiva en la comprobación de los recursos económicos disponibles. 2.2. Dificultades prácticas en la implementación del «means test». 2.3. Aumento de las «barreras de entrada» al procedimiento. 2.4. La mejora de la posición del acreedor con garantía. 2.5. Incremento de cautelas y restricciones. 2.5.1. Solución al problema del fraude en el cambio de domicilio previo a la solicitud. 2.5.2. El triple límite del «discharge». III. Reflexión final.

Resumen: Estudio acerca del singular sistema que regula el sobreendeudamiento e insolvencia del consumidor en los Estados Unidos de América, a la luz de la reforma operada en 2005. Análisis específico tanto de la aplicación práctica del means test como de las diferentes «barreras de entrada» al procedimiento. Comentario acerca de los límites y restricciones que sufre la posibilidad del discharge. USA.

Palabras clave: BAPCPA, consumidor, insolvencia, sobreendeudamiento,

Abstract: This is a study of the particular system which regulates consumer over-indebtedness and insolvency in the United States of America, in view of the 2005 reform. It includes specific analysis of both the practical application of the means test as well as the different «entry barriers» to the procedure. The limits and restrictions of discharge are discussed.

Key words: BAPCPA, consumer, insolvency, over-indebtedness, USA. 


\section{Consideraciones previas}

A diferencia de lo que sucede en Europa, donde el tratamiento de las crisis económicas de los consumidores se produce de manera fragmentaria y, en muchos casos, patentemente insuficiente ${ }^{1}$, en los Estados Unidos de Norteamérica el procedimiento que intentaba, de alguna forma, aliviar situaciones como las referidas, contaba con una sólida tradición. Sin embargo, tal sistema, tras la entrada en vigor de la reforma operada por la Ley de protección de los consumidores y de prevención del abuso en las declaraciones de concurso de 2005, ha sufrido un importante «retroceso». La entrada en vigor de la «Bankruptcy Abuse Prevention and Consumer Protection Act» (S. 256, en lo sucesivo $B A P(P A)$, reforma que culmina la lucha iniciada años atrás por la industria del crédito americana (especialmente por los empresarios que comercializan tarjetas de crédito), supone una severa ruptura con la tradición de USA en el tratamiento de las crisis económicas de los consumidores².

El sistema actual trata, a través de diferentes medidas, entre las que sobresale la puesta en marcha de un exigente sistema objetivo de comprobación de los medios económicos, de reducir de manera drástica el número de consumidores que se acogen a la declaración prevista en el Capítulo 7 en favor de los que se ven obligados a afrontar una reorganización a medio plazo del pago de sus deudas en el mucho más exigente Capítulo 13. La inmediata liquidación de las deudas una vez que se ceden los bienes disponibles «no protegidos» («nonexempt assets»), que propicia el Capítulo 7, se restringe de forma sensible para fomentar, una vez que se verifica una mínima disponibilidad de ingresos, la reorganización de aquéllas en un plan de pagos a ejecutarse en un periodo de entre 3 y 5 años. También la creciente aparición de dificulta-

1 Ver, en relación con el sistema español pero también para un primer acercamiento al panorama europeo, Vega Álvarez, M.I.: La protección jurídica del consumidor sobreendeudado e insolvente, Cizur Menor, 2010.

2 La filosofía de los Estados Unidos de América en el tratamiento legal de las crisis económicas, sean éstas de empresarios o de consumidores, ha estado vinculada siempre a un sentimiento de «indulgencia» o comprensión absolutamente extraño a la visión que se tiene del fenómeno en, v. gr., Europa o Japón. Lejos de estigmatizar social o económicamente a los quebrados, el sistema jurídico les permitía iniciar una nueva vida que, en numerosos ocasiones, terminaba por generar actividades empresariales de indudable éxito. Lo que a ojos de ordenamientos jurídicos cercanos resultaba inasumible por excesivamente generoso, en los Estados Unidos de América encontraba el indudable apoyo de la sociedad civil, que parecía consciente de la importancia que el crédito y la iniciativa empresarial tenían en la fortaleza de la economía del país. Ver Martin, N.: "American Bankruptcy laws: encouraging risk-taking and entrepeneurship» en http:// usinfo.state.gov/journals/ites/0106/ijee/martin.htm 
des en el acceso al procedimiento supone un handicap importante que puede lastrar, de forma severa, el éxito final del proceso ${ }^{3}$.

La oportunidad y justificación de la reforma en relación con los intereses de los consumidores resulta, cuando menos, ciertamente cuestionable, pues, aun cuando el planteamiento general, desde el punto de vista del mercado, pueda ser defendible, lo cierto es que la manera concreta de ejecutarla adolece no sólo de errores técnicos evidentes sino también de planteamientos demagógicos de base que inciden de forma determinante en el diseño final de la norma; todo ello provoca que la posibilidad del consumidor, aquejado por una súbita enfermedad o forzado a hacer frente a un divorcio y a sus consecuencias económicas, de acogerse al «fresh start», durante tanto tiempo cuasigarantizado por las benevolentes leyes estadounidenses, se desvanezca en un marasmo de requisitos previos y pruebas fácilmente manipulables por aquellos que, paradójicamente, cuentan con más medios. En definitiva, se pierde la razón de ser original de la norma, que pasa de prevenir posibles abusos a decantarse claramente en favor de los intereses de las instituciones de crédito, en lo que sin duda es un "golpe de gracia» a los fundamentos tradicionales con que se afrontaba el tratamiento de las crisis económicas de los consumidores en el ordenamiento jurídico de USA ${ }^{4}$.

El generoso tratamiento del sobreendeudamiento de los consumidores en el derecho concursal estadounidense contaba, hasta la reforma que ahora se analiza, con una consolidada tradición. La Ley de 1898 se apoyaba en una premisa básica, como era ofrecer al «honest but unfortunate» deudor una rehabilitación inmediata e incondicionada, de la mano de la cesión de sus bienes «no protegidos» ${ }^{5}$. El Capítulo 7 del Código de Quiebras (11 U.S.C., §§ 701-707; §§ 721 $728 ; \S \S 741-750 ; \S \S 761-767 ; \S \S 781-784)$ era el instrumento que permitía a los deudores acceder a este «beneficio», el cual, además,

3 Ver, sobre el impacto de la reforma en función del capítulo aplicable, Caldie, E. y Corey-Edstrom, K.: «Individual Chapter 11 Bankruptcies in Minnesota after BAPCPA: Uncharted Territory», en http://www.larkinhoffman.com/files/OTHER/KCEJan2011.pdf

4 Algunos autores llegan a calificar la posibilidad del consumidor estadounidense de aspirar al «nuevo comienzo», tras la reforma operada por BAPCPA, de «Cruel and ephemeral illusion». Tabb, C.J.: "The death of consumers bankruptcy in the United States?», University of Illinois College of Law, Law and Economics Working Papers Series. Working Paper 00-29 (septiembre de 2001), p. 5.

5 No obstante, la doctrina es consciente de que la norma no sólo tenía por objeto proteger al consumidor ante un eventual sobreendeudamiento sino, además, revitalizar el mercado del crédito en los Estados Unidos de América. White, M.J.: «Abuse or protection? Economics of bankruptcy reform under BAPCA», University of Illinois Law Review (2007), pp. 302-304. 
no se encontraba condicionado ni al consentimiento de los acreedo$r^{r}{ }^{6}$, ni a la prueba de que el sobreendeudamiento se había producido por un infortunio insoslayable, ni al pago de un porcentaje mínimo de la deuda, lo que, unido a que apenas un $5 \%$ de las declaraciones que se acogían a ese capítulo contaban verdaderamente con bienes que realizar en favor de los acreedores ${ }^{7}$, convertían a este procedimiento en una oportunidad inmejorable para que el deudor se viera libre de todas sus deudas manteniendo además sus futuros ingresos al margen de reclamación alguna. Tan sólo a algunos deudores, respecto de los que se evidenciaba un comportamiento "fraudulento» (ocultación de bienes o perjurio, entre otros actos reprobables) se les denegaba la rehabilitación solicitada, del mismo modo que las pensiones de alimentación de los hijos o las indemnizaciones debidas por daños y perjuicios causados dolosamente no se veían condonadas en virtud de este procedimiento.

Para aquellos consumidores sobreendeudados pero que contaban con un cierto patrimonio, existía, al margen de la propiciada por el ya citado Capítulo 7, otra posibilidad, como es la contemplada en el Capítulo 13 (11 U.S.C., §§ 1301-1308; §§ 1321-1330). En este procedimiento el deudor conservaba la propiedad de sus bienes, si bien tenía que asumir un plan de pago aplazado de sus deudas a medio plazo, plan que debía de ser aprobado por el juzgado competente, dilatándose la rehabilitación del deudor en tanto en cuanto el plan no se hubiere cumplido con éxito. Lo más destacado de este proceso de «reorganización» es que el mismo resultaba plenamente voluntario para el deudor, no pudiendo en ningún caso los acreedores obligar al consumidor a solicitar este tipo de declaración ni compelerle a transformar una declaración instada de acuerdo con el Capítulo 7 en una regida por el Capítulo 13. En definitiva, el consumidor sobreendeudado era libre para calibrar, de acuerdo con su situación patrimonial actual y sus posibilidades de ingresos futuros, cuál de los dos procedimientos le convenía más, resultando muy renuentes los tribunales a rechazar solicitudes instadas bajo el Capítulo 7 en base a las expectativas de futuro del deudor solicitante. Es precisamente esta renuencia la que origina el movimiento de reforma auspiciado por la industria del crédito esta-

${ }^{6}$ Lo cual supuso, en su momento, una novedad relevante respecto a las normas vigentes con anterioridad. Ver Tabb, C.J.: «The historical evolution of the bankruptcy discharge», American Bankruptcy Law Journal, núm. 65 (1991), pp. 325-370.

7 Tabb, C.J.: "Consumer Bankruptcy after the Fall: United States Law under S. 256», Illinois Law and Economics Working Paper Series. Working paper LE05-031, p. 2. Disponible en http://papers.ssrn.com/pape.tar?abstract id=859654 
dounidense, la cual sostiene que una gran parte de los consumidores que se acogen a la liquidación inmediata y posterior rehabilitación del Capítulo 7 son «can-pay debtors», es decir, deudores que podrían pagar una cantidad sustancial de sus deudas bajo el plan de pagos previsto en el Capítulo 13. Por ello, postulan una reforma que, si no haga obligatorio para determinados deudores este segundo procedimiento sí, al menos, les obligue a superar un exigente «means test» en el caso de que pretendan acogerse a la generosa «descarga» que propicia el Capítulo 7.

Los movimientos en pro de la reforma del procedimiento, que tienen como objetivo último redireccionar de forma obligatoria a los solicitantes del Capítulo 7 que se supone que tienen posibilidades económicas para afrontar un plan de pagos aplazado hacia el correspondiente Capítulo 13, tienen origen en los años treinta y, desde entonces, y a pesar de sufrir continuos reveses en el Congreso, no han cejado en el empeño de implantar un «test» que permita calibrar si el deudor es verdaderamente merecedor de la rehabilitación casi automática que propicia el Capítulo $7^{8}$.

En respuesta a los continuos intentos de la industria del crédito, apoyados en muchas ocasiones por estudios estadísticos que intentaban demostrar que gran parte de los consumidores que se acogían al Capítulo 7 tenían ingresos suficientes para afrontar con garantías una reorganización del pago de sus deudas como la que preveía el Capítulo 13, el Congreso de los Estados Unidos de América, en 1984, accedió a reformar el sistema de tal forma que los tribunales pudieran rechazar las solicitudes que pretendían beneficiarse de la liquidación ofrecida por el Capítulo 7 si apreciaban que tal solicitud constituía un «substancial abuse». Sin embargo, y a pesar de que, en un primer momento, tal posibilidad parecía filtro suficiente como para evitar que,

8 Ver resumen de los continuos intentos del lobby, integrado por empresas del sector bancario y crediticio, en especial por empresas emisoras de tarjetas de crédito, en Tabb, C.J.: «Consumer Bankruptcy after the Fall (...), pp. 4-7, y Jensen, S.: «A Legislative History of the Bankruptcy Abuse Prevention and Consumer Protection Act of 2005», American Bankruptcy Law Journal, núm. 79 (2005), pp. 485-569. En contra del movimiento reformista se posicionó mayoritariamente tanto el sector académico como el judicial, así como los abogados especialistas en la asistencia al sobreendeudado. Dickerson, A.M.: "Regulating bankruptcy: public choice, idelology, \& beyond», Washington University Law Review, núm. 84, p. 1.866, npp. 29, reproduce literalmente la muy expresiva intervención que, al respecto, desarrolló el Senador Wellstone en el Congreso: "You are hard pressed to find a bankruptcy judge that supports this legislation. You are hard pressed to find a bankruptcy law professor, a bankruptcy expert of any kind, anywhere, any place in the U.S.A. that backs this bill. This bill was written for the lender. It is that simple». 
al menos teóricamente, «can-pay debtors» pudieran acogerse al Capítulo 7, existían diferentes circunstancias que dejaban insatisfechos a los reformistas. En primer lugar, el hecho de que el concepto de «substancial abuse» no fuera definido con precisión en la norma, permitiendo a los tribunales que apreciaran, con cierto grado de discrecionalidad, si efectivamente ese consumidor solicitante disponía o no de capacidad de pago suficiente para afrontar una reorganización de la mano del Capítulo 13, suponía, en la práctica, que, dependiendo del juez que valorara la situación económica del deudor, un mismo caso se considerara "abuso» en una zona y se admitiese en otra, lo que, como es obvio, generaba una elevada inseguridad jurídica. En segundo lugar, y aún desestimada la solicitud al haberse apreciado el referido "abuso», el deudor no se veía obligado en ningún caso a afrontar el plan de pagos del Capítulo 13, resultando su asunción de todo punto voluntaria y pudiendo, como otra alternativa, simplemente renunciar a la solicitud planteada. Todo ello provoca que los impulsores de la reforma se declaren insatisfechos con la misma y persistan, si cabe con más fuerza, en la solicitud de un «means test» que, de forma absolutamente objetiva, permita apreciar con total claridad si el deudor puede o no acogerse a la liquidación automática que le ofrece el Capítulo $7^{9}$.

De la mano una vez más de estudios estadísticos que avalaban la capacidad de pago a futuro de muchos de los consumidores que solicitaban con éxito la «liquidación» de deudas del Capítulo $7^{10}$, y tras alguna que otra nueva negativa por parte del Congreso ${ }^{11}$, finalmente la industria consigue su objetivo con la reforma que ve la luz en abril de 2005.

9 Tales esfuerzos se detallan en Tabb, C.J.: «A century of regress or progress? A political history of bankruptcy legislation in 1898 and 1998», Bankruptcy Development Journal, núm. 15 (1999), pp. 344-353.

10 El estudio, que se sufragó con cargo a fondos de la industria crediticia estadounidense (concretamente gracias a la financiación de VISA USA y Mastercard International, dos de las más importantes empresas emisoras de tarjetas de crédito), se puede consultar en: Neubig, T.; Jaggi, G. y Lee, R.: «Chapter 7 Bankruptcy Petitioner's Ability to Repay under H.R. 833: The National Perspective», American Bankruptcy Institute Law Review, núm. 7-1 (1999), disponible en http://68.72.75.1/abidata/online/lawrev/spring99/ Nuebig_sp99.html\#n*

11 El informe emitido en 1997 por la comisión del Congreso, entonces presidida por la Profesora de Harvard, Elizabeth Warren, fue abrumadoramente contrario a la implantación de un «means test» (únicamente dos de los nueve miembros de la comisión se mostraron favorables a su establecimiento). 


\section{La nueva regulación. Planteamiento general}

\subsection{Una nueva perspectiva en la comprobación de los recursos económicos disponibles}

La base sobre la que descansa el impulso del cambio durante tanto tiempo promovido por la industria crediticia americana es la implantación de un «means test» que sea capaz de evaluar con éxito el futuro nivel de ingresos de los deudores que pretenden acogerse al Capítulo 7. Semejante análisis se basará en criterios objetivos y ampliará de manera sustancial el concepto de «substancial abuse» que tan insatisfecho había dejado al lobby crediticio durante la vigencia de la norma anterior. Así, aquellos consumidores que no superen el exigente «examen», se verán obligados a someterse al plan de pagos del Capítulo 13 si es que pretenden la rehabilitación de sus deudas, pues la solicitud bajo el Capítulo 7 se verá desestimada de inmediato. Y, de acuerdo con el diseño del test, la mera expectativa de un modesto «remanente» en las perspectivas económicas futuras del consumidor, bastará para situar al deudor ante semejante tesitura.

La filosofía que justifica la implantación de la medida apuntada se basa en la evidente «injusticia» que supone que un deudor con, en teoría, capacidad para pagar parte de sus deudas con cargo a ingresos futuros, se vea absolutamente libre de las mismas al ceder sus bienes «no protegidos» en el Capítulo 7, disfrutando posteriormente de una existencia desahogada, si no de lujo ${ }^{12}$. Esta es más o menos la base sobre la que los teóricos favorables a la reforma asentaban la imposición

12 Los diferentes Estados detallan en normas ad hoc cuáles son los bienes que el deudor puede conservar si prospera su solicitud de concurso. El Estado de Nueva York realiza una enumeración no exhaustiva de esos bienes "protegidos» en la que se evidencia su extensión y, en algún caso, también su singularidad, que sin duda tiene que ver con la peculiar concepción que en USA se tiene del estado social. La relación comprende los siguientes conceptos:

- Clothing and household goods such as household furniture, a stove, refrigerator, radio, television, cookware, tableware, sewing machine, books and pets.

- Cash up to \$2,500 (this can include an income tax refund), unless an exemption for real property (real estate) is claimed.

- Alimony, maintenance or child support owed to the debtor.

- The right to receive certain awards and benefits such as Social Security, SSI, Unemployment Compensation, Public Assistance Veteran's Benefits, Disability Benefits, Worker's Compensation Benefits and Personal Injury Awards (up to \$7,500 not including pain and suffering and actual monetary loss).

- Pensions, Keogh, 401(K), 403(B) Plans, IRA and most annuities.

- A cemetery plot. 
del «means test» ${ }^{13}$. En efecto, tal visión resultaría difícilmente asumible para el resto de la sociedad, que hace frente mayoritariamente a sus compromisos de pago en tiempo y forma. Sin embargo, el hecho de que existan situaciones como la descrita no significa que las mismas constituyan el más común de los supuestos a que da solución el Capítulo 7, sino más bien la excepción que confirma la regla, resultando aquél un planteamiento muy permeable a la demagogia que, como buena parte de la doctrina se ha encargado de poner de manifiesto, puede hacer "pagar a justos por pecadores», al establecer una medida desproporcionada en relación con el fin que se pretendía ${ }^{14}$.

El problema de la reforma es, en nuestra opinión, que afronta el sobreendeudamiento de los consumidores y su crecimiento en los últimos $a_{n ̃ o s}{ }^{15}$ desde una perspectiva monolítica, haciendo responsables de tal

- A motor vehicle, up to $\$ 2,400$ in market value over any financed amount owed on the vehicle (la enumeración ejemplificativa comentada se encuentra en el folleto informativo que, con el título Personal Bankruptcy: is it right for you? edita, en abril de 2007, el City Bar Justice Center del Colegio de Abogados de Nueva York, y que se encuentra disponible en http://www.abcny.org/Publications/pdf/ Individual_Bankruptcy_Pamphlet.pdf)

13 Resultan muy expresivos, a estos efectos, algunos extractos de la intervención del Senador Grassley, principal impulsor de la reforma, en el Congreso el 20 de junio de 2000: "With large numbers of bankruptcies occurring at a time when americans are earning more than ever, the only logical conclusion is that some people are using bankruptcy as an easy out. The basic policy question we have to answer is this: should people with means who declare bankruptcy be required to pay at least some of their debts or not? Right now, the current bankruptcy system is oblivious to the financial condition of someone asking to be excused from paying his debts. The richest captain of industry could walk into a bankruptcy court tomorrow and walk out with his debts erased. And, as I described earlier, the rest of america will pay higher prices for goods and services as a result.

(...) I think that the american people deserve the whole truth. The truth is that these bankruptcies represent a clear and present danger to america's small businesses. Growth among small businesses is one of the primary engines of our economic success. The truth is bankruptcies hurt real people. Sometimes that will be inevitable. But it's not fair to permit people who can repay to skip out on their debts».

Intervención disponible íntegramente en la página web del senador Grassley: http:// grassley.senate.gov/public/index.cfm?FuseAction=PressReleases. Detail\&PressRelease_ id=3f6bbdc7-ad08-4e08-a7b9-73837385d58a\&Month=6\&Year=2000

14 Warren, E.: "A principled approach to consumer bankruptcy», American Bankruptcy Law Journal, núm. 71 (1997), pp. 483-495, denuncia el planteamiento torticero de los reformistas al evidenciar cómo los ingresos «netos» de los más desfavorecidos, lejos de haberse incrementado, han descendido desde la década de los 80 , por lo que achacar el incremento de los procedimientos a un "abuso» del sistema no deja de ser una falacia; también Tabb, C.J.: «Consumer Bankruptcy after the Fall (...)», pp. 7-8, critica el análisis demagógico realizado por los sectores que apoyaron BAPCPA.

15 De las 780.455 solicitudes de 1994 se pasa a las 2.039.214 de 2005, año de la reforma, lo que supone casi una triplicación en apenas diez años. En 2006, tras la en- 
fenómeno a los deudores y al abuso que éstos vienen realizando de la rehabilitación casi automática que ofrece el Capítulo 7, sin detenerse a analizar, ni por un momento, la posible cuota de responsabilidad que, en esa coyuntura, pueda atribuirse a la arriesgada concesión de créditos al consumo ${ }^{16}$ así como a la excesiva penalización de sus impagos, especialmente en caso de descubiertos en tarjetas de crédito ${ }^{17}$. Es sin duda paradójico que la industria del crédito proteste por el aumento en el porcentaje de deuda impagada en los últimos años resultando, al mismo tiempo, que su beneficio en ese periodo ha experimentado subidas superiores al $40 \%{ }^{18}$. La situación, por tanto, no parece tan dramática como se pretendía hacer ver, al menos en términos absolutos. De hecho, la política de comercialización de los productos de las compañías de crédito sigue siendo tan agresiva como siempre, sin que el incremento de sobreendeudamiento denunciado haga reconsiderar a los empresarios sus estrategias de marketing ${ }^{19}$. La sencillez en la obten-

trada en vigor de BAPCPA, la cifra se reduce drásticamente a 597.965, aunque en 2007 repuntan hasta las 822,590 en lo que supone el inicio de un incesante incremento hasta el día de hoy $(1,074,108$ en $2008,1,412,838$ en 2009 y 1,536,799 en 2010). No obstante, y al margen del número total de declaraciones instadas, el porcentaje entre el Capítulo 7 y el 13, que antes de la reforma presentaba una relación de un $70 \%$ frente a un $30 \%$, ahora se ha estabilizado en torno a un $60 \%$ frente a un $40 \%$, por lo que, si bien el número de expedientes ha experimentado, por el momento, una importante rebaja, la redistribución pretendida entre los capítulos, supuestamente uno de los objetivos principales de la reforma, no parece demasiado relevante. Ver estadísticas completas y actualizadas en la página web del American Bankruptcy Institute: http://www. abiworld.org/AM/AMTemplate. cfm?Section=Home\&TEMPLATE=/CM/ContentDisplay. cfm\&CONTENTID=49785 Estos datos parecen hacer buenas las pesimistas previsiones de parte de la doctrina en cuanto a las cantidades que los acreedores iban a «recuperar» tras la reforma, las cuales no iban en ningún caso a compensar el esfuerzo presupuestario de poner en marcha el nuevo sistema, dado el escaso número de "can pay debtors» que iban a aflorar. Ver por todos Culhane, M.B. y White, M.M.: «Taking the new consumer bankruptcy model for a test drive: means-testing real chapter 7 debtors», American Bankruptcy Institute Law Review, núm. 7 (1999), PP. 27-32.

16 Ver Lawless, R.M.: "The Paradox of Consumer Credit», University of Illinois Law Review (2007), PP. 347-374. Ver, asimismo, inciso final de la nota 20.

17 Ausubel, L.M.: "Credit card defaults, credit card profits, and Bankruptcy», American Bankruptcy Law Journal, núm. 71 (1997), PP. 249-250.

18 Tabb, C.J.: en Illinois Law and Economics Working Paper Series. Working paper LE05-031, P. 9.

19 Brobeck, S.: «Recent Trends in Bank Credit Card Marketing and Indebtedness», estudio realizado para la Consumer Federation of America en julio de 1998, disponible en http://www.abiworld.org/AM/PrinterTemplate.cfm?Section=General\&Template=/ CM/HTMLDisplay.cfm\&ContentID=34817\&FuseFlag=1, evidencia, entre otros datos interesantes, que durante el periodo 1992-1998 las empresas de tarjetas de crédito en Estados Unidos aumentaron el crédito disponible en un $256 \%$ y el mailing a potenciales clientes en un $255 \%$, mientras que el global de la deuda únicamente aumentó en un 
ción de una tarjeta de crédito, en primer término, la facilidad a la hora de negociar ampliaciones de crédito o de concentrar varios créditos en uno, con el consiguiente incremento de coste, y los elevados tipos de interés previstos en caso de impago parecen, todas ellas, razones suficientes como para que la industria que plantea semejantes condiciones no pueda alegar desconocimiento ni sorpresa ante las consecuencias que, todas esas circunstancias, finalmente ocasionan ${ }^{20}$. Sin embargo, y de manera coherente con el planteamiento «irresponsable» recién expuesto, ninguna medida de contención o de limitación es invocada por parte de los impulsores de la reforma que, de alguna forma, afecte a los proveedores del crédito, resultando únicamente los consumidores los que han de ser «controlados» en sede de declaración concursal.

$137 \%$. Y todo esto mientras solicitaban con urgencia la reforma que ahora se analiza. Un ejemplo claro de la agresividad imperante en las técnicas de comercialización de tarjetas de crédito en USA lo tenemos en el sector de los estudiantes universitarios, un tercio de los cuales dispone de cuatro o más tarjetas de crédito. Este «fenómeno» propició, en su momento, que el estado de Nueva York limitara severamente, mediante ley (Ch. 964, de 2004) que entró en vigor el 1 de julio de 2005, el marketing realizado en los Campus por estas compañías, ejemplo que hasta el momento han seguido ya una docena de estados. Ver http://www.bizjournals.com/buffalo/stories/2004/11/22/daily14. html y, en relación con los últimos movimientos, http://chronicle.com/news/article/3218/ consumer-group-urges-colleges-to-limit-credit-card-marketing

20 Las estadísticas muestran cifras tremendamente significativas acerca de la idiosincrasia de la industria del crédito estadounidense y, especialmente, de la dedicada a la emisión de tarjetas de crédito. Así, en 2004, alrededor de 640 millones de tarjetas de crédito se encontraban en circulación en Estados Unidos, produciéndose un incremento del 46\% para el periodo 1996-2005; asimismo, habían sido enviadas seis mil millones de solicitudes postales, a razón de unas 20 por cada ciudadano, y cada «americano medio» disponía de cuatro tarjetas. Aún resulta más esclarecedor que los intereses y comisiones por retraso en los pagos, el aplazamiento de los mismos (únicamente un $39 \%$ satisfacía su saldo a mes vencido) y los excedidos de límite, hayan generado para la industria unos ingresos de 43.000 millones de dólares (tan sólo los correspondientes a retrasos se habían incrementado en un 115\% para el periodo 1995-2005). Ver datos estadísticos en http://www.cardratings.com/creditcardstatistics.html Más significativos resultan todavía los datos que analizan específicamente el comportamiento de las empresas del sector crediticio en relación con los consumidores que, una vez sobreendeudados, han solicitado la rehabilitación de los Capítulos 7 O 13. El 96.1\% recibe ofertas de tarjetas de crédito en el año posterior a solicitar la apertura del procedimiento; asimismo, reciben, de media, en ese mismo periodo, catorce ofertas de préstamo por mes, frente a las seis que recibe el consumidor americano medio y, lo que es aún más sorprendente, el $88 \%$ de esos deudores asegura que, en esas comunicaciones comerciales, figuran referencias explícitas a su situación de crisis económica, lo que demuestra la consciencia del empresario a la hora de diseñar semejante política de marketing. Ver Porter, K.: «Bankrupts profits: the credit industry's business model for postbankruptcy lending», University of lowa Legal Studies Research Paper, 9-10 (2007), pp. 1-64. Disponible en http://www.sottolaw.com/katherineporter.pdf 
Pero al margen de este planteamiento absolutamente sesgado de la situación, creemos que tampoco se ha valorado suficientemente la relación coste-beneficio que la reforma iba a causar en el panorama legal estadounidense en cuanto al tratamiento de las crisis económicas de los consumidores. Así, frente a perspectivas de incremento de cobro de deuda de los acreedores no garantizados, propiciadas por la reducción de solicitudes de Capítulo 7 en favor de las del Capítulo 13, que resultaban además ciertamente sobrevaloradas ${ }^{21}$, se ha producido un incremento sensible en los costes de tramitación del procedimiento ${ }^{22}$, los cuales, al margen de lastrar el sistema de forma severa, difícilmente van a ser compensados por las «recuperaciones» anunciadas. Verdaderamente, a la luz de lo expuesto, no parece que el esfuerzo legislativo realizado merezca la pena en términos absolutos 23 .

Al final, el análisis equivocado y, lo que es peor, interesado del problema, la desproporción evidente a la hora de afrontarlo y, por último y como ahora se va a comprobar, los errores técnicos que lastran la implantación del «means test», propician no únicamente el fracaso de la reforma de cara a la consecución de los objetivos que ésta se planteaba sino, muy probablemente, la crisis global del sistema legal que afrontaba el sobreendeudamiento del consumidor en los Estados Unidos de América ${ }^{24}$.

\subsection{Dificultades prácticas en la implementación del «means test»}

El «means test», en su búsqueda de futuros ingresos que permitan calificar la solicitud del consumidor bajo el Capítulo 7 de «presumptive abuse», y al margen de ulteriores intervenciones "correctoras» del tribunal en base a la aparición de «especiales circunstancias», funciona

21 Ver nota 14.

22 Una primera previsión del Congressional Budget Office cifraba el coste de implantar BAPCPA, para el periodo 2006-2010, en 392 millones de dólares, al que habría que sumar los incrementos que sufren también los deudores y los representantes legales de estos. Informe completo disponible en http://www.govtrack.us/congress/ billreport.xpd?bill=s109-256\&type=cbo

23 Tabb, C.J., en Illinois Law and Economics Working Paper Series. Working paper LE05-031, p. 7, apunta, muy gráficamente, que para analizar la oportunidad y el éxito de la reforma hay que preguntarse si «the game is worth the candle».

24 Tabb, C.J., en University of Illinois College of Law, Law and Economics Working Papers Series. Working Paper 00-29 (septiembre de 2001), pp. 11-17, y Warren, E.: American Bankruptcy Law Journal, núm. 71 (1997), p. 506, quien habla de una «destrucción» absoluta del sistema. 
de acuerdo con una sencilla fórmula, consistente en computar los ingresos mensuales del deudor, restar una serie de gastos predeterminados y multiplicar el resultado por 60 meses. Si la cifra resultante es superior, bien a 10.000 dólares en todo caso, bien a 6.000 dólares o al $25 \%$ del total de los créditos que no gocen de garantía ni de privilegio general sobre el patrimonio del deudor, tomando como referencia la mayor de las dos cifras, el consumidor no habrá superado el means test ${ }^{25}$. En definitiva, si se detecta, para un consumidor sobreendeudado con deudas principalmente de consumo y con ingresos familiares por encima de la media del Estado, una capacidad de "repayment» de 100 dólares mensuales es muy posible que la solicitud sea calificada como «presumption of abuse»y, en consecuencia, se vea imposibilitado para acogerse a la rehabilitación que ofrece el Capítulo 7.

Pero este mecanismo, aparentemente sencillo, comienza a evidenciar problemas una vez que se empieza a ejecutar. Así, e independientemente de alguna que otra vacilación a la hora de determinar cuál es la media del Estado de cara a calcular la legitimación del solicitante para someterse al «means test» ${ }^{26}$, resultan muy fácilmente distorsionables los parámetros que se habían previsto para evaluar, de forma pretendidamente objetiva, los ingresos mensuales actuales del solicitante, cuya cuantía resultará clave para detectar los posibles «remanentes» futuros.

A este respecto, uno de los principales problemas que se plantea es el cálculo del «current monthly income». Por «current monthly income» se entiende la media mensual de ingresos del deudor, independientemente de la fuente de los mismos ${ }^{27}$ y de si están o no sujetos a tributación, durante el periodo de seis meses inmediatamente anterior a la solicitud de concurso.

Una de las primeras cuestiones que merece siquiera un análisis crítico es el hecho de que únicamente se utilice, para determinar cuál será el nivel de pago a medio plazo del deudor solicitante, su historial de ingresos anterior a la fecha de presentación de la solicitud. Si bien es cierto que en muchos casos el conocimiento de la historia resulta útil para conocer el futuro, quizás sea éste uno en los que menos fiable re-

2511 U.S.C. $\S 707$ (b)(2)(A)(i)(I) y (II).

26 El U.S. Census Bureau publica dos tipos de medias por Estado, una basada en el tamaño global de la familia y la otra en el número de perceptores de ingresos por unidad familiar. Ver http://census.gov/hhes/www/income/medincsizeandstate.html.

27 Se incluyen asimismo los ingresos del cónyuge en caso de solicitud conjunta y cualesquiera otros recibidos de terceras personas que contribuyan a los gastos del hogar. Los únicos ingresos que se encuentran excluidos son los «Social Security benefits» y los pagos recibidos en compensación por haber sufrido crímenes contra la humanidad, crímenes de guerra o actos de terrorismo. 
sulta, al haber sobrevenido por fuerza un suceso que, en la mayoría de las ocasiones, genera un cambio severo en las expectativas patrimoniales del consumidor, responsable, en último término, de la situación de crisis económica desencadenada. Resulta por tanto sorprendente que el legislador no se haya percatado de tal circunstancia, insistiendo en una exégesis detallada de la situación económica de los seis meses anteriores que, en muchos casos, puede provocar impresiones absolutamente erróneas, cuando no auténticas paradojas ${ }^{28}$. Este peculiar «sistema» también es propicio para sufrir ciertas prácticas perversas que, en un intento por salvar el means test, y previa cuidadosa planificación, pueden reducir durante ese periodo y de manera intencionada ingresos que venían siendo ordinarios y que, curiosamente, desaparecen de forma súbita para esa concreta franja temporal29. Quizás este intento por atender únicamente a datos ciertos y comprobables que han acontecido en el pasado se deba al afán de evitar, a toda costa, la intervención moderadora de tribunales, como sucedía en el sistema anterior. Sin embargo, y atendiendo a los riesgos y disfunciones expuestos, creemos que el margen de discrecionalidad e inseguridad que provoca en ocasiones tal intervención, se ve compensado sobradamente por el análisis más matizado y menos mecánico que las situaciones de crisis económica del consumidor, por complejas y singulares, merecen.

Otra de las cuestiones que plantean problemas prácticos evidentes es la determinación de cuáles de los gastos son «deducibles» y cuáles, por el contrario, van a ser computados de cara a evaluar una futura capacidad de reintegro del deudor. En este aspecto, la norma se aparta

28 Tabb, C.J., en Illinois Law and Economics Working Paper Series. Working paper LE05-031, p. 15, señala, muy acertadamente, que en un método que intenta detectar posibles «excedentes» en el futuro para atender al pago de deudas, el pasado no es necesariamente un prólogo útil, presentando algunos ejemplos especialmente significativos; así, comenta el caso de un consumidor abocado a una situación de crisis económica por causa de un despido reciente, al cual se le computarán sus ingresos como trabajador en activo durante varios de los seis meses anteriores de cara a «evaluar» expectativas de futuros ingresos, lo cual carece de fundamento; en sentido contrario, evidencia el supuesto de un estudiante de último curso de licenciatura sobreendeudado que ha firmado un contrato multimillonario con una prestigiosa firma de abogados para prestar servicios una vez que finalice sus estudios, destacando que, muy probablemente, este individuo no tendría problema alguno para superar el means test, al no computarse esas expectativas.

29 Ver White, M.J., en University of Illinois Law Review (2007), pp. 292-293, quien reproduce diferentes supuestos de reducción «interesada» de ingresos. No obstante, este tipo de actitudes pueden ser combatidas de la mano de la presunción de «mala fe», como se prevé en norma ad hoc -11 U.S.C. § 707 (b)(3)—, aunque la invocación de tal circunstancia requiere, como resulta obvio, de un análisis casuístico que, además de ralentizar el proceso, vuelve a dotarlo de un cierto componente de discrecionalidad. 
del criterio que sigue el Capítulo 13, que hacía depender del juez la decisión última acerca de qué gastos eran necesarios para el soporte y mantenimiento del deudor y de las personas que de él dependían y qué gastos, por contra, habían de ser reputados como «disposable income». Así, en ese empeño de los reformistas por eliminar cualquier resquicio de discrecionalidad ${ }^{30}$ y con la coartada de asegurar, en todo momento, la predecibilidad del resultado del «means test» así como la sencillez a la hora de proceder a su cálculo, se explicitan con detalle todos y cada uno de los gastos que van a ser considerados como «deducibles», sin que, como se va a comprobar a continuación, los objetivos apuntados se hayan asegurado en absoluto.

En este sentido, para determinar los conceptos integrantes de la primera categoría de gastos «deducibles», entre los que se incluyen aquellos destinados al mantenimiento del deudor y de su familia («living expenses»), se toma como referencia la nómina de gastos que el Internal Revenue Service permite a los condenados por evasión fiscal, de tal forma que se produce, como destaca parte de la doctrina, una muy curiosa analogía de trato entre los condenados por delitos fiscales y los consumidores sobreendeudados, primero, y, lo que es más sorprendente, si cabe, entre la administración tributaria y los acreedores privados ${ }^{31}$.

Pero, independientemente de la controvertida filosofía que inspira la equiparación comentada, también genera problemas el cálculo concreto de determinados gastos, dada su dependencia, en ocasiones, del lugar concreto de residencia del solicitante. Así sucede, v. gr., con los gastos autorizados para alojamiento y servicios públicos, que pueden oscilar más de 300 dólares mensuales dependiendo del condado concreto en el que resida el consumidor. Tal circunstancia puede inducir a planificar, antes de solicitar la declaración de concurso, un cambio de residencia que incremente sustancialmente el nivel de gastos deducibles y que permita, en última instancia y gracias a esa «triquiñuela», superar el means test ${ }^{32}$. No cabe duda que semejante sistema origina

30 Sobre el tema, ver Williams, J.F.: «Distrust: the rhetoric and reality of means-testing», American Bankruptcy Institute Law Review, núm. 7 (1999), pp. 105-131.

31 Tabb, C.J.: University of Illinois College of Law, Law and Economics Working Papers Series. Working Paper 00-29 (septiembre de 2001), p. 22.

32 Lo mismo sucede en relación con los gastos autorizados para transporte, respecto de los cuales un deudor avispado que «juegue» con un oportuno cambio de residencia y con la adquisición sobrevenida de uno o dos vehículos, puede conseguir un incremento mensual de gastos «deducibles» de más de 80 dólares de cara a superar el «means test». Semejantes actuaciones sólo pueden ser atajadas de la mano de la intervención del juez, quien puede desestimar la solicitud al detectar patente mala fe (ver nota 29). 
situaciones intrínsecamente injustas y, desde luego, muy alejadas de la pretendida objetividad a que se aspiraba con la reforma ${ }^{33}$.

De cualquier forma, las posibilidades de «manipular» preventivamente el resultado final del "means test» exceden de las que proporciona la sobredimensión de los «living expenses» afectando, asimismo, a aquellos deudores que opten por matricular a sus hijos en un colegio privado (lo que constituye una opción realmente interesante ya que puede llegar a proporcionar una «deducción» total, para el periodo de cinco años, de 7.500 dólares). Asimismo, los que acumulen una elevada nómina de deudas garantizadas resultarán paradójicamente beneficiados respecto de los que tengan asumido un menor nivel de deuda de semejante naturaleza, al preverse una «deducción» específica por tal concepto ${ }^{34}$. Aún resulta más grave la «manipulación» de aquellos que demoran interesadamente el pago de créditos privilegiados (entre los que se cuentan, lógicamente, pensiones para el sustento y cuidado de los hijos) con la intención de liquidar deuda no garantizada, conscientes de que los primeros, a diferencia de los segundos, son considerados como gasto «deducible».

Por último también es sorprendente que el tribunal, ante la tesitura de desestimar una solicitud por "abuso», pueda no tener en cuenta las contribuciones monetarias que el deudor realiza o haya realizado a organizaciones religiosas o caritativas reputadas («qualifyed»)35, a pesar de que las mismas no se encuentran explícitamente incluidas como gasto «deducible» de cara a la evaluación a realizar en el «means test». Este tratamiento «privilegiado» de semejantes aportaciones no deja de resultar intrínsecamente extraño en un proceso que tiene por objeto tratar una situación de sobreendeudamiento. No obstante, posiblemente en lo que se refiere a contribuciones a confesiones religiosas tal «concesión» resulte explicable en el singular contexto social de USA, de la misma forma que ese mismo contexto sirve para justificar la inclusión como

33 No obstante, de cara a calcular la cuantía de los gastos englobados bajo el concepto "otros gastos necesarios», entre los cuales se incluyen partidas tan variopintas como las integradas por el cuidado de los niños, la atención sanitaria o la suscripción de un seguro de vida, la norma ya utilizaba referencias ciertamente indeterminadas como la que hacía alusión a la «razonabilidad» de tales desembolsos. Este planteamiento hace necesaria la intervención «integradora» del juez, la cual, no por lógica y acertada, deja de ser ciertamente contraria a la filosofía que inspiraba la reforma del «means test», absolutamente contraria a cualquier margen de discrecionalidad.

34 Ver 11 U.S.C. § 707 (b)(2)(A)(iii). El deudor podrá, en consecuencia, priorizar el pago de las deudas no garantizadas a costa de retrasar el de las garantizadas con la única intención de colocarse en mejor situación de cara al cómputo del «means test».

35 Ver 11 U.S.C. $\S 707$ (b)(1). 
gasto «deducible» de los desembolsos que sean «razonablemente» necesarios para proteger al deudor o a su familia de la violencia doméstica o de los que se vengan destinando a la atención de personas mayores, enfermas crónicas o discapacitadas del entorno del deudor o de su familia más próxima ${ }^{36}$. Además, en la consideración acerca de la procedencia o necesidad de los gastos comentados se vuelven a detectar elementos que afectarán sin duda a la pretendida seguridad jurídica del nuevo sistema, incidiendo de forma determinante en la predecibilidad del resultado final del proceso así como en el nivel de conflictividad que éste genera.

Resulta, asimismo, clave el tratamiento que se dé a la cifra final obtenida. Así, tras calcularse los ingresos mensuales netos del deudor, una vez descontadas las correspondientes deducciones, se multiplican por los 60 meses que, eventualmente, integrarían el periodo de cinco años durante el cual el consumidor sobreendeudado, de no superar el «means test», se vería obligado a reorganizar el pago de su deuda. La cifra de referencia respecto de la cual se comparará el resultado obtenido será la menor de las siguientes: el $25 \%$ del total de la deuda no garantizada y no privilegiada del solicitante o 6000 dólares, tomando la mayor de ambas cantidades; o la cifra de 10.000 dólares. Si los ingresos estimados «netos» fueran superiores a cualquiera de estos conceptos, entonces habría de presumirse el «abuso» ${ }^{37}$.

Traduciendo el proceso a cifras concretas de ingresos mensuales disponibles por deudor solicitante, hay que concluir que, si tales ingresos son inferiores a 100 dólares mensuales, el consumidor no va a tener problema alguno en superar el «means test»; por el contrario, si la cifra supera los 166 dólares mensuales, se detectará el presunto «abuso», rechazándose la solicitud de acogerse al procedimiento previsto en el Capítulo 7 y abocando al deudor a la reorganización que plantea el Capítulo 13. No obstante, y a pesar de no haber superado el "means test», se permite la continuación del procedimiento de acuerdo con el Capítulo 7 siempre y cuando el deudor sea capaz de

36 En relación con este último concepto resulta llamativo que la «deducción» se conceda siempre y cuando el gasto viniera ya realizándose y no cuando éste se presenta de forma sobrevenida. Ver 11 U.S.C. § 707 (b)(2)(A)(ii)(II).

37 «In considering under paragraph (1) whether the granting of relief would be an abuse of the provisions of this chapter, the court shall presume abuse exists if the debtor's current monthly income reduced by the amounts determined under clauses (ii), (iii), and (iv), and multiplied by 60 is not less than the lesser of-

(I) 25 percent of the debtor's nonpriority unsecured claims in the case, or $\$ 6,000$, whichever is greater; or

(II) $\$ 10,000 »(11$ U.S.C. $\S 707$ (b)(A)(i)(I)(II). 
acreditar la existencia de «circunstancias especiales», concepto que, a pesar de no encontrarse expresamente definido en la norma, los impulsores de la reforma asimilaron en el Congreso a, $v$. gr., el padecimiento de problemas graves de salud o la obligación de asumir deberes de índole militar ${ }^{38}$. Para los dos supuestos referidos el resultado es claro y, por lo general, no presenta dificultades; el problema se plantea para aquellos consumidores cuyo nivel de gastos disponible, una vez realizado el cálculo, oscila entre los 100 y los 166 dólares mensuales. En relación con éstos, se ha de evaluar si, de acuerdo con este «excedente», el consumidor es capaz de afrontar, en los 60 meses previstos para la reorganización, el pago de más de un $25 \%$ de su deuda no garantizada, en cuyo caso su solicitud se verá, asimismo, rechazada.

Estos resultados se pueden también sistematizar atendiendo al nivel global de deuda no garantizada que tenga cada deudor. Así, se distinguirían tres segmentos. Uno primero para aquellos consumidores cuya deuda global no garantizada estuviese por debajo de 24.000 dólares, respecto de los cuales el "abuso» se presumiría una vez que superasen la cantidad neta de 6.000 dólares para los 5 años previstos. Un segundo segmento, que integrarían los deudores con un nivel de deuda no garantizada que oscile entre 24.000 y 40.000 dólares, los cuales incurrirían en "abuso» siempre y cuando sus ingresos netos supusieran una cifra superior al $25 \%$ del total de la deuda no garantizada. Y, por último, un tercer grupo compuesto por aquellos consumidores cuya cota de deuda no garantizada se sitúe por encima de 40.000 dólares, para los cuales el "abuso» sería apreciado cuando percibiesen, durante los sesenta meses de referencia, ingresos netos globales por importe superior a 10.000 dólares, independientemente del porcentaje de deuda no garantizada que dicha cantidad suponga.

En relación con estos resultados, e independientemente de que los mismos permiten, con un alto índice de fiabilidad, prever con anticipación suficiente cuál va a ser el resultado final del «means test», uno de los objetivos perseguidos por BAPCPA, lo cierto es que la aplicación se-

38 No obstante, la posibilidad que el deudor tiene de alegar la existencia de «circunstancias especiales» para evitar la presunción de abuso, medida que en sí misma puede suponer un importantísimo instrumento que ayude a evitar situaciones intrínsecamente injustas, se ve en cierta medida lastrada, no sólo por el esfuerzo probatorio que tiene que realizar el consumidor, acreditando de forma exhaustiva la existencia y cuantía de esos gastos o ajustes invocados, respecto de los que ha de declarar su veracidad bajo juramento, sino, sobre todo, por el temor que los asesores tienen a ser sancionados si, finalmente, el deudor, aún alegando las singularidades aludidas, no es capaz de superar el means test. Ver epígrafe 3.3. "Aumento de costes: el agravamiento de la responsabilidad del letrado». 
vera de la fórmula puede resolver determinados supuestos de forma, si no «perversa», sí abiertamente contraria a la que se suponía era la filosofía inspiradora de la reforma, como era conseguir, a través de la transformación de procedimientos tramitados bajo el Capítulo 7 en planes de pagos propios del Capítulo 13, que parte de la deuda que permanecía impagada con el generoso sistema anterior, se satisficiese ahora con la reorganización a que obligaban las cantidades «excedentes» detectadas. Sin embargo, y de acuerdo con la situación a que lleva la aplicación rigurosa de la fórmula desarrollada en el "means test», no son infrecuentes casos en los que deudores con un nivel de deuda no asegurada muy elevado ( $v$. gr., más de 1.000.000 de dólares) y con ingresos totales (una vez descontadas las oportunas deducciones) para el periodo de cinco años que apenas superan los 10.000 dólares, se ven obligados a afrontar su crisis económica a través del Capítulo 13 por el mero hecho de superar esa cifra crítica, por mucho que con la misma apenas vayan a ser capaces de reintegrar a sus acreedores un 1\% del total de la deuda. Pero aún es más paradójico el supuesto contrario, en el que deudores capaces de satisfacer más de un $50 \%$ de su deuda no asegurada con cargo a los «remanentes» previstos en un futuro próximo, resultan sorprendentemente rehabilitados bajo el Capítulo 7 por la única razón de que, siendo aquélla inferior a 24.000 dólares, su expectativa de ingresos «netos» no supera los 6.000 dólares (v. gr., deuda no garantizada de 10.000 dólares e ingresos netos previstos de 5.900 dólares supone la superación automática del «means test» con una capacidad de «repayment» del 59\%; cabría preguntarse si este deudor es o no un "can pay debtor», quien, de acuerdo con las recurrentes explicaciones de los principales impulsores de la reforma, resultaba el principal objetivo de la misma...).

No parece defendible tampoco que la distancia entre la superación segura del «means test» y la consideración inequívoca de la solicitud como «abusiva» se cifre únicamente en la percepción de 67 dólares mensuales ${ }^{39}$, resultando asimismo criticable que el afán por hacer de-

39 Hay que recordar, además, que la no superación del «means test» ocasiona ahora, a diferencia de lo que sucedía con la norma anterior, la intervención del funcionario encargado de tramitar la solicitud, quien se verá obligado a instar de forma casi automática, bien el desistimiento, bien la «conversión» de la petición sustanciada, siempre y cuando cuente, para este supuesto, con el consentimiento del deudor. La reforma obliga al deudor a colaborar activamente en el proceso que da cauce al «means test», compeliéndole a presentar una declaración que incluya un calendario de ingresos y gastos de acuerdo con los parámetros previstos en la norma — § 521. 11 U.S.C. § 707 (b) (2)(c) - . Semejante declaración es exigible incluso cuando al deudor, por sus circunstancias, no le sea aplicable la prueba, siendo la mera ausencia de su presentación causa suficiente para desestimar la solicitud. 
pender el resultado final de la prueba de criterios estrictamente objetivos, provoque, en ocasiones, que la diferencia entre acceder a la beneficiosa liquidación que ofrece el Capítulo 7 y la obligación de asumir la reorganización a que aboca el Capítulo 13 dependa del cómputo u omisión de un solo dólar. En un tema de tanta trascendencia social y económica como es el del sobreendeudamiento de los consumidores, la intervención moderadora del tribunal en supuestos como los aludidos resulta no sólo conveniente sino absolutamente necesaria, pues la misma, lejos de minorar la efectividad del sistema, coadyuvaría decisivamente a su consolidación práctica, evitando absurdos que pudieran minar, como ahora sucede, su fundamentación teórica. El beneficio obtenido en términos de confianza compensaría con creces la supuesta merma de agilidad y certeza que sufriría el procedimiento, el cual, por otro lado, tampoco se ve enteramente libre de la intervención puntual e integradora del tribunal ${ }^{40}$.

\subsection{Aumento de las «barreras de entrada» al procedimiento}

Además de los problemas en el diseño e implantación del means test la reforma comporta un sensible incremento en las obligaciones de índole burocrático que el deudor ha de cumplimentar, lo que, en última instancia, conlleva la existencia de dificultades adicionales de cara al acceso al procedimiento. Asimismo, los costes del proceso sufren una importante subida debida, en parte, a la agravación de la responsabilidad del letrado. Esta circunstancia también incrementa las dudas del deudor sobreendeudado, una vez que se plantea presentar la pertinente solicitud.

Uno de los primeros «trámites» con que el deudor ha de cumplir si es que desea acogerse a la rehabilitación que ofrece el procedimiento concursal es el que le obliga, con carácter previo (en los seis meses anteriores a la presentación de la solicitud), a someterse a asesoramiento prestado por una agencia sin fines de lucro, con el objeto último de que el deudor sea capaz de tomar decisiones conscientes e informadas acerca de los diferentes procedimientos a seguir en un futuro para afrontar su crisis económica ${ }^{41}$. Al margen de su utilidad, cuestionada

40 Ver nota 29.

4111 U.S.C. § $109(\mathrm{~h})(1)$. Sobre la necesidad de interpretar de forma más flexible el precepto, sin necesidad de proceder directamente a desetimar la solicitud, ver Satorius, J.: "Strike or dismiss: interpretation of the BAPCPA, 109(h) credit counseling requirement», Fordham Law Review, núm. 75, pp. 2.231-2.268. Artículo disponible íntegramente en http://law.fordham.edu/publications/articles/500flspub7651.pdf 
en ocasiones por la singular naturaleza del momento elegido42, así como por el coste del informe en cuestión ${ }^{43}$, es probablemente la exigencia del certificado en sí misma la que puede resultar un obstáculo de cara al buen fin de la solicitud, dado el lógico estado de preocupación, si no de ansiedad, que presentará el deudor, acuciado por problemas que probablemente le impidan organizar, con la debida anticipación y diligencia, su calendario para el periodo previo a la solicitud ${ }^{44}$. Únicamente en aquellos casos en que el programa, por las razones que sea, no se encuentre disponible o cuando el deudor no pueda cumplimentarlo al encontrarse prestando servicios en las fuerzas armadas, se excepcionará del cumplimiento de la obligación reseñada. Una vez pre-

42 Ver, al respecto, el informe de la United States Government Accountability Office (GAO) de abril de 2007, en el que se evidencia que, a diferencia de lo que sucede con los programas de educación al deudor posteriores a la solicitud, mayoritariamente valorados por los afectados, los programas de «credit counseling» se reputan ciertamente ineficaces dada la situación normalmente deseperada del consumidor, abocado ya a instar una declaración concursal, sin otra alternativa procedimental válida. Informe disponible íntegramente en http://www.gao.gov/new.items/d07203.pdf. Ver, también, el interesante análisis de Newman, M.: "Bapcpa's new section 109(h) credit counseling requirement: is it having the effect congress intended?», Utah Law Review (2007), pp. 489-519.

43 A principios de 2007 la Executive Office for US Trustees había aprobado, como proveedores oficiales del servicio de asesoramiento y educación del deudor, tanto previo como posterior a la solicitud, a más de 500 agencias, de las cuales aproximadamente un $20 \%$ cobraban apenas 50 dólares por el servicio y otro 10\% ofrecía la posibilidad de rebajar el precio para aquellos deudores sin capacidad de pago. No obstante, la doctrina crítica con la reforma reprocha, tanto la ausencia de definición, de cara a aplicar el referido «descuento», del "ability to pay» como el hecho de que las tarifas a aplicar y sus condiciones varíen en función del lugar concreto en que se desarrolle el procedimiento. Ver Gerdano, S.J.: "BAPCPA's early returns: statistics, key issues to date», disponible en la web del American Bankruptcy Institute, http://www.abiworld.org/AM/Template. cfm?Section=Home\&CONTENTID=48041\&TEMPLATE=/CM/ContentDisplay.cfm, p. 3. En cualquier caso, a estos 50 dólares habría que sumar otra cantidad similar por la asistencia al curso de "educación del consumidor» previo a la rehabilitación del mismo. A pesar de lo modesto de la cantidad no hay que olvidar la delicada situación económica en la que se encuentra el consumidor, que hace que resulte aconsejable la reducción, en lo posible, de tales tarifas.

44 No obstante, hay que constatar que las agencias «habilitadas» para prestar la asesoría han hecho importantes esfuerzos para facilitar la obtención del certificado, de tal forma que, hoy en día, los programas no sólo son accesibles en persona sino también a través del teléfono o Internet; además, varias de las agencias autorizadas por la administración para impartir tales cursos prestan sus servicios en diferentes idiomas, lo cual resulta fundamental en un país de naturaleza eminentemente multicultural como son los Estados Unidos de América. Ver lista completa de las Credit Counseling Agencies autorizadas por la administración USA en http://www.usdoj.gov/ust/eo/bapcpa/ ccde/cc_approved.htm 
sentada la declaración también resulta obligatorio cumplimentar un curso de administración financiera personal, que habrá de desarrollarse en los 45 días anteriores a la primera reunión con los acreedores, y que es requisito sine qua non para obtener la rehabilitación deseada, lo que comporta un nuevo gasto a computar en el coste global del procedimiento.

Otra de las cuestiones que influye, de forma determinante, en el incremento de las dificultades de acceso al procedimiento es que cualquier solicitud de concurso presentada por un deudor consumidor requiere de la presentación de múltiples y complejos formularios, entre los que, independientemente de la presentación formal de la petición, se incluyen hasta diez diferentes planillas que detallan exhaustivamente cuál es la situación económica y patrimonial actual del deudor, así como cuáles son sus perspectivas de futuro. Por si alguna de las situaciones económicamente relevantes que afectan al deudor no encuentra reflejo en los conceptos recogidos en los formularios, se ha de presentar, asimismo, un informe de estado financiero en el que conste toda aquella información adicional que, a tales efectos, resulte significativa.

Al margen de respetar escrupulosamente los plazos exigidos, de manera que si a los 45 días de iniciado el procedimiento no se han cumplimentado las obligaciones documentales señaladas el caso será automáticamente desestimado, el deudor ha de extremar también su diligencia para reflejar, con precisión y exactitud, todos aquellos datos que le son requeridos, so pena de incurrir en falsedad que generaría, en algún caso, responsabilidad adicional del letrado.

Por último, y dado el agravado régimen de responsabilidad que, tras la reforma, le es aplicado al letrado encargado de asistir al deudor, este mismo habría de encargarse de comprobar la corrección de las informaciones proporcionadas por el consumidor, para lo cual es necesario realizar una investigación previa que acarrea un importante incremento del coste global del procedimiento para el deudor, lo que redunda en una nueva "barrera», esta vez económica, de cara a acceder al procedimiento ${ }^{45}$.

Esta reforma del $\S 707$ (b) resulta muy controvertida. Si el tribunal considera que el letrado ha violado la norma 9011 de las Federal Rules of Bankruptcy Procedure, bien entablando una solicitud "frívola» o presentando documentos inapropiados, puede sancionarle en un do-

45 En relación con la reforma y sus consecuencias respecto del régimen de responsabilidad del letrado, ver Vance, C.E. y Cooper, C.: «Nine traps and one slap: attorney liability under the new bankruptcy law», American Bankruptcy Law Journal, núm. 79 (2005), pp. 283-332. 
ble sentido. Por una parte, obligándole a asumir las costas del procedimiento y, por otra, imponiéndole una multa. La responsabilidad del abogado se agrava sensiblemente, de forma que su firma al pie de la solicitud acredita, por un lado, la realización de un estudio previo acerca de la viabilidad de la petición a tramitar y, por otro, una adecuada fundamentación fáctica y legal de la solicitud, inspirada en la buena fe y no constitutiva de «abuse» -11 U.S.C. § 707 (b)(4)(C)—. Asimismo, el abogado declara, con esa suscripción, desconocer posibles informaciones falsas o incorrectas que puedan aparecer entre los documentos presentados en el procedimiento. Naturalmente, este severo régimen de responsabilidad disuade en numerosas ocasiones a los letrados de apoyar o aconsejar la presentación de solicitudes, especialmente de aquellas cuyo éxito final dependa de la consideración de «circunstancias especiales» que dejen sin efecto la no superación del «means test». En consecuencia, únicamente aquellas solicitudes bajo el Capítulo 7 cuyo buen fin se encuentre asegurado (deudores con ingresos por debajo de la media del estado o cuya superación del «means test» se encuentre casi garantizada o, en su defecto, deudores que puedan invocar «circunstancias especiales» que resulten patentes e incontestables) resultarán avaladas fácilmente por asistencia letrada. Otra de las consecuencias evidentes, al margen de la natural «desincentivación», es el incremento de los honorarios que los abogados pasarán a percibir por tal concepto, al resultar ahora, de acuerdo con el tenor de la reforma, verdaderos garantes de la solicitud formulada; el agravamiento de la responsabilidad del letrado ocasiona, por sí solo, una elevación de su «coste», pero también la obligación de realizar un estudio exhaustivo previo acerca de las circunstancias en las que puede fundamentarse la petición del deudor incide negativamente en tal sentido, redundando, todo ello, en una inhibición generalizada de solicitudes.

\subsection{La mejora de la posición del acreedor con garantía}

Uno de los más relevantes cambios que la reforma opera en el procedimiento es la reformulación del "strip down» de las deudas garantizadas. Tal «técnica» suponía, para el deudor, la posibilidad de reducir el monto de una deuda garantizada al valor mismo de la garantía. Así, un deudor que solicita una declaración bajo el Capítulo 13 podía, antes de la reforma, computar como deuda garantizada únicamente el valor de ejecución de la garantía (más el correspondiente interés), pagándose el resto del montante junto al resto de deudas no garantizadas. Esta posibilidad resultaba absolutamente coherente pues se suponía 
que el acreedor, de haber embargado finalmente el bien, únicamente hubiera podido obtener el valor de la venta del mismo.

BAPCPA introduce severas restricciones a semejante «técnica» de forma que, si la deuda garantizada tiene su origen en la adquisición de un vehículo a motor (lo que resulta muy frecuente) el importe de aquélla no se podrá «reducir» al valor de la garantía si tal vehículo fue adquirido para uso personal del deudor, si la deuda se contrajo en los dos años y medio anteriores a la solicitud o, finalmente, si la deuda es de "purchase money» (la deuda se contrae con la intención de comprar el mismo bien que garantiza el pago de la misma). Además, tras la reforma, el «strip down» se prohíbe para todo tipo de bien en el caso de que la deuda se hubiera contraído en el año anterior a la solicitud. El efecto de estas restricciones es obvio: los deudores que pretendan desarrollar un procedimiento bajo el Capítulo 13, al tener que pagar mayor cantidad de deuda garantizada, verán como la admisión de su solicitud se hace más complicada y, en el caso de que finalmente se tramite, la cumplimentación con éxito del plan de pagos de cara a obtener la rehabilitación también se verá seriamente amenazada. El resultado de la reforma en este sentido es, pues, paradójico. Por un lado, una norma que intentaba incrementar las declaraciones tramitadas bajo el Capítulo 13, convierte a este procedimiento en más inasequible y, por otro, beneficia a los acreedores garantizados en perjuicio de los no garantizados cuando habían sido éstos los que impulsaron decisivamente la reforma ${ }^{46}$.

46 Los efectos perversos de esta reforma ya habían sido anticipados en las críticas que había recibido la S. 306, muy similar en el fondo a la que ahora se analiza. Se había llegado a cuantificar el tanto por ciento de procedimientos que, bajo el Capítulo 13, se verían desestimados de acuerdo con la nueva norma, estimándolo en casi un $20 \%$. Ver, al respecto, la muy expresiva alocución realizada por el Senador Russ Feingold en el Comité para asuntos judiciales del Senado el 27 de febrero de 2001 (disponible íntegramente en http://judiciary.senate.gov/oldsite/rf022701e.htm): "Section 306 is called "Giving Secured Creditors Fair Treatment Under Chapter 13.»It ought to be called "Giving Certain Secured Creditors Preferred Treatment Under Chapter 13, » because it favors those who make car loans over other secured creditors and over unsecured creditors.

(...) What the bill does is to eliminate the cramdown for any car that is purchased within five years of bankruptcy. That means that even though the vehicle that secures the loan has lost much of its value, the entire amount of the debt must be repaid in a Chapter 13 plan. This gives special treatment to the lender, but more importantly, it will make it much more difficult for a Chapter 13 plan to work. And that will hurt people who want to pay off their debts in an organized fashion under Chapter 13.

In answer to my written question, Bankruptcy Judge Randall Newsome supplied a detailed example that shows how the elimination of the cramdown option will hurt both debtors and creditors. In his example, a debtor with a seven year old car who files under Chapter 13 under current law will be able to pay off his car loan up to the value of the car with interest and make a meaningful payment of his unsecured debts over the 
Otro de los beneficios inesperados que la reforma proporciona a los acreedores de deudas garantizadas es el originado por el cambio en el sistema de valoración de las garantías. Si antes de la reforma la opción entre el valor de reposición o el valor de ejecución dependía del uso que se atribuyese al bien dado en garantía, ahora se opta por utilizar siempre la primera referencia, lo que resulta perjudicial para los intereses del deudor y claramente beneficioso para el acreedor, quien recibe un evidente incremento en relación con lo que hubiese obtenido si, simplemente, hubiese ejecutado la garantía.

Por último, una de las cuestiones que resultaban más controvertidas en la práctica judicial ${ }^{47}$ es resuelta por BAPCPA de forma perjudicial para los intereses del deudor. Así, una vez que el deudor al corriente de sus pagos explicita su intención de conservar un bien doméstico que servía de garantía sobre una deuda, se planteaba la posibilidad de mantener la propiedad de tal bien sin más requerimiento que continuar atendiendo los pagos. Tras la reforma, no le queda más opción que, bien amortizar, bien renovar la obligación, pues de otra forma la suspensión se levantaría y el acreedor podría ejecutar el bien ${ }^{48}$.

3 year duration of his Chapter 13 plan. But with the elimination of the cramdown in the bill, he would, he would have no choice but to file in Chapter 7 and allow the car lender to repossess his vehicle. And his unsecured creditors would get nothing. I ask that Judge Newsome's letter to me providing the details of this example be included in the record.

Most people file Chapter 13 cases because they want to keep their cars. The cramdown allows them to reduce their car payments to a reasonable amount, leaving enough money to pay off other secured creditors and make a repayment plan work. According the Chapter 13 trustees, who know what they are talking about since they deal with these cases day in and day out, this single provision of the bill will increase the number of unsuccessful Chapter 13 plans by 20 percent. And Judge Newsome states that if this bill becomes law, Chapter 13 will essentially be eliminated as an option for people who wish to hold on to their cars.

(...) The anti-cramdown provision undermines the efficacy of Chapter 13. All the experts tell us that. And I have to point out the irony here. The avowed purpose of proponents of this bill is to move people from Chapter 7 discharges to Chapter 13 repayment plans, yet the bill undermines Chapter 13. I will support an amendment to eliminate this particular provision that is really a gift to the auto industry at the expense of other secured creditors.»

47 Ver Waxman, N.W.: «Redemption or Reaffirmation: The Debtor's Exclusive Means of Retaining Possession of Collateral in Chapter 7, " University of Pittsburg Law Review, núm. 56 (1994), pp. 187-204.

48 Principe, P.R.: "Did BAPCPA Eliminate the "Fourth Option" for Individual Debtors' Secured Personal Property?», American Bankrupcty Institute Journal (24 de octubre de 2005), pp. 6, 48 y 49, analiza con detalle el alcance de la reforma y sus consecuencias (http://www.abiworld.org/AM/Template.cfm?Section=Home\&TEMPLATE=/CM/ ContentDisplay.cfm\&CONTENTID=41589\#2a, página web del American Bankruptcy Institute). 


\subsection{Incremento de cautelas y restricciones}

\subsubsection{SOlución Al PROBLEMA DEL FRAUdE EN EL CAMBIO DE DOMICILIO PREVIO A LA SOLICITUD}

De acuerdo con la norma anterior a la reforma, el deudor podía beneficiarse de leyes de determinados Estados que le permitían, de forma sensible, incrementar las exenciones por razón de vivienda habitual. Era relativamente frecuente, por tanto, que en las fechas previas a la presentación de la solicitud el deudor cambiara de domicilio, adquiriendo una nueva vivienda en uno de esos Estados o, incluso, ampliando la ya existente, de forma que conseguía, así, transformar propiedades no protegidas en bienes exentos. La reforma operada por BAPCPA intenta poner coto a estas estrategias, introduciendo criterios más rigurosos a la hora de determinar cuál es el domicilio hábil a efectos del cálculo de las exenciones. Así, establece que el domicilio relevante será el del deudor en la fecha en la que presenta la solicitud sólo si se encontraba domiciliado en tal Estado los dos años anteriores a la interposición de la petición. Si el deudor no hubiera tenido domicilio durante ese periodo en ningún Estado, entonces el lapso temporal a tener en cuenta serán los seis meses inmediatamente anteriores a esos dos años. Por último, si en esos seis meses el deudor hubiera tenido domicilios en diferentes Estados, habría que tomar como referencia aquel Estado en el que hubiera mantenido el domicilio más tiempo.

Otro de los límites que introduce la nueva norma en relación con las «homestead exemptions» es aquel que impide transformaciones de propiedad no exenta en exenta en los diez años anteriores a la presentación de la solicitud, si el objetivo de tal operación es obstaculizar, demorar o defraudar a un acreedor. Asimismo, y sin necesidad de probar intención alguna de fraude, limita a 125 dólares la exención, si el incremento alegado se ha producido en los 1.215 días previos a la solicitud, a no ser que el aumento se corresponda con la renegociación de la deuda de una antigua vivienda ubicada en el mismo Estado.

Por último, y atendiendo a la «alarma social» originada por el escándalo de Enron ${ }^{49}$, limita también a 125 dólares la exención cuando el

49 Resultó difícil de asumir para la sociedad estadounidense que muchos de los principales ejecutivos de Enron, principales responsables de su crisis, pudieran beneficiarse de amplias exenciones por las mansiones que poseían en Estados como Texas y Florida, donde las leyes a este respecto son muy generosas con el deudor. Shenon, P.: «Enron's many strands: the executives; home as shield from creditors is under fire», The New York Times (4 de abril de 2002), sección C, p. 1, reproduce muy expresivamente el ambiente previo al movimiento de reforma: «Without a change, Enron executives will con- 
deudor ha sido condenado por determinados delitos o tiene pendiente el pago de deudas originadas por la comisión de fraudes en materia de valores ${ }^{50}$.

\subsubsection{EL TRIPLE LÍMITE DEL «DISCHARGE»}

Se implanta un triple límite que afecta tanto al plazo, como a la cuantía y naturaleza de las deudas «descargables».

La norma anterior a la reforma ofrecía al deudor que se había beneficiado de la rehabilitación propiciada por el Capítulo 7 la posibilidad de volver a disfrutar de ese procedimiento una vez que trascurrieran seis años, mientras que, tras la entrada en vigor de BAPCPA, el periodo se amplía a ocho años.

Asimismo, se introduce un nuevo límite temporal para aquellos deudores que soliciten una declaración bajo el Capítulo 13 si antes habían obtenido una rehabilitación de acuerdo con los Capítulos 7, 11 o 12, de tal forma que, para que sea aceptada, habrán de transcurrir al menos cuatro años entre una y otra. En el supuesto de que la descarga hubiera sido obtenida bajo un Capítulo 13 no se admitirá una nueva solicitud bajo ese mismo Capítulo si esta se produce en los dos años siguientes.

Así como la primera reforma resulta razonable, dada la naturaleza liquidatoria del Capítulo 7, la introducción de restricciones temporales a la hora de acogerse a un Capítulo 13, resulta extraña a su propia filosofía, consistente en la optimización de los recursos del deudor, disponibles en un futuro próximo, para, de esa forma, satisfacer la mayor parte de deuda posible de la forma más organizada y menos traumática posible. El propio procedimiento parece diseñado para evitar «abusos», sin que parezca necesario el establecimiento de límites temporales estrictos que, por otra parte, abocarían al consumidor a situaciones límite que resultarían nefastas no sólo para él sino también para los acreedores.

También hay que destacar que los planes de reorganización propiciados por el Capítulo 13 se alargan de 3 a 5 años para aquellos deu-

tinue to live in multimillion-dollar mansions, even as their former employees struggle to find a new paycheck or to cover their rent (declaraciones del Senador demócrata Herb Kohl) (...) For people who've lost everything as a result of the wrongful actions by these executives, it adds insult to injury (declaraciones de un abogado experto en quiebras).»

50 Las normas modificadas en materia de exenciones por vivienda han sido 11 U.S.C. § 522 (b)(3)(A), 11 U.S.C. § 522 (o), 11 U.S.C. § 522 (p) y 11 U.S.C. § 522 (q). 
dores con ingresos iguales o superiores a la media del Estado, no pudiendo el deudor obtener la rehabilitación en tanto en cuanto no culmine el calendario de pagos preestablecido.

La presunción de fraude que impide el descargo de determinadas deudas sufre un muy sensible y, en ocasiones, injustificado ensanchamiento. Así, se consideran compras de bienes de lujo aquellas que alcancen la mera cifra de 500 dólares, frente a la anterior que los cifraba en 1.225 dólares, ampliando además el periodo durante el cual se controlarán tales «dispendios» de sesenta a noventa días. También sufren esa extensión los anticipos de efectivo, que se reputarán no descargables a partir de 750 dólares (frente a los 1.225 dólares que se permitían antes de la reforma), ampliándose asimismo el periodo a tener en cuenta de sesenta a setenta días. Es obvio que esta medida persigue que mucha de la deuda generada por la utilización de las tarjetas de crédito ( $v$. gr. disposiciones de efectivo a crédito) se convierta en no descargable, atendiendo, una vez más, a los intereses de los poderes fácticos que representan las entidades de crédito estadounidenses.

Los préstamos para estudios, independientemente de la naturaleza del prestamista, y a no ser que se pruebe por parte del deudor un grave infortunio, van a resultar, asimismo, no descargables tras la entrada en vigor de BAPCPA ${ }^{51}$.

Por último, y al margen de este triple límite reseñado, la generosa nómina de tipos de deuda susceptibles de ser descargados únicamente bajo el Capítulo 13, considerada tradicionalmente como un intento del legislador por promover este tipo de procedimiento y denominada muy expresivamente como «super-discharge», se ve drásticamente reducida tas la reforma operada por la S. 256. De esta forma, a los límites previos a la reforma, que alcanzaban a las pensiones de manutención, los préstamos para estudio o al reintegro de sanciones penales, se añaden ahora, entre otros, algunas deudas tributarias, las deudas por desfalco o malversación o las contraídas como consecuencia del resarcimiento pendiente de daños causados dolosamente con resultado de lesiones o muerte tras la oportuna acción civil. En definitiva, y tras BAPCPA, las únicas deudas que siguen pudiendo acogerse a esa descarga privilegiada son aquellas que tienen su origen en acuerdos adoptados en pro-

51 No obstante, existen ya dos proyectos de ley (S. 511 y S. 1561) que pretenden restaurar la posibilidad de descargar limitadamente ese tipo de deudas, bien introduciendo un límite temporal respecto del inicio del pago del préstamo (siete años), bien atendiendo a la naturaleza privada de la financiación obtenida. Para más información ver Chen, D.: "Student loans in bankruptcy», CRS Report for Congress (26 de julio de 2007). Disponible en http://assets.opencrs.com/rpts/RS22699_20070726.pdf 
cesos de separación o divorcio y las relacionadas con el impuesto que grava la renta, siempre y cuando tengan una antigüedad mayor de tres años respecto a la declaración y no se haya intentado evasión o fraude alguno en torno a las mismas.

\section{Reflexión final}

En primer lugar, y al margen de los problemas concretos que la reforma está ocasionando en diferentes fases de los procedimientos afectados, lo cierto es que una de las conclusiones más evidentes, seis años después de la entrada en vigor de BAPCPA, es que la pretensión de incrementar la seguridad jurídica y garantizar a toda costa la predecibilidad de los distintos procesos, principal justificación y objetivo del movimiento reformista, no sólo no se ha conseguido sino que, en ciertas cuestiones, como las expectativas de los acreedores de deuda garantizada en el sector de automoción, el cálculo de los ingresos disponibles para hacer frente a un plan de pagos del Capítulo 13 o, incluso, la posibilidad de elección del deudor a la hora de solicitar la declaración, han empeorado sensiblemente, como se deduce del incremento de la conflictividad judicial en los últimos años ${ }^{52}$.

En relación con ese objetivo, una de las principales medidas de la nueva norma era eliminar, en la medida de lo posible, elementos que pudieran introducir un margen de discrecionalidad en la aplicación de la ley ${ }^{53}$. Sin embargo, los hechos han evidenciado que esa decisión no resulta apropiada en una materia tan sensible socialmente como es el sobreendeudamiento de los consumidores, especialmente cuando éste se produce de forma sobrevenida y a consecuencia de hechos respecto de los cuales el deudor carece de influencia alguna ${ }^{54}$. La exigencia in-

52 Waldron, T.F.: «Principled principles of statutory interpretation: a judicial perspective after two years of bapcpa», American Bankruptcy Law Journal, núm. 81 (2007), pp. 195-232. Sólo en 2010 más de 1.500 .000 personas solicitaron el procedimiento, llegando a los niveles de 2004, previos a la reforma.

53 No ayuda en absoluto la existencia de conceptos ambiguos en los formularios oficiales de «means test», lo que ha originado confusión y discrepancias en la doctrina jurisprudencial obligando a la Corte Suprema a intervenir aunque, lamentablemente, sólo se ha pronunciado en relación con parte de los términos controvertidos, por lo que la inseguridad, en una cuestión tan sensible como esta, continúa. http://www. betterbankruptcy.com/bankruptcy-blog/2011/05/the-bapcpa-today/

54 Ver el interesante artículo de Himmelstein, D.U.; Warren E.; Thorne, D. y Woolhandler, S.: «lllness and injury as contributors to bankruptcy», Health Affairs (2 de febrero de 2005) —disponible en http://content.healthaffairs.org/cgi/content/full/hlthaff. w5.63/DC1-, donde, abundando en las singulares características del sistema sanitario 
discriminada de obligaciones documentales múltiples o de atender diversos cursos de formación resulta absurda en determinadas situaciones que hubieran requerido, sin duda, una singular consideración por parte de la norma ${ }^{55}$.

Otro de los problemas que se ha puesto en evidencia es que el intento de BAPCPA por evitar a toda costa el «abuso», mediante la rigurosa aplicación del «means test», genera en ocasiones el efecto de impedir a deudores «honestos» que puedan acogerse a los beneficios de la rehabilitación que ofrece el Capítulo 7, tanto a causa de la ausencia de discrecionalidad referida como de la redacción confusa que genera, paradójicamente, una aplicación desigual de la norma en los diferentes tribunales ${ }^{56}$. Los datos estadísticos existentes prueban, además, que la gran mayoría de los deudores que pretenden acogerse al procedimiento cuentan con deudas que exceden sobradamente sus ingresos, hasta el punto de que un $44 \%$ de los mismos percibe menos de 20.000 dólares anuales, situándose apenas por encima de lo que en los Estados Unidos de América se considera el nivel de pobreza para una familia de cuatro miembros. Asimismo, su nivel de endeudamiento medio es mayor que el de aquellos consumidores que no buscan la rehabilitación ofrecida por el sistema y las causas que originan su sobreendeudamiento son, mayoritariamente, los problemas de salud sobrevenidos, las situaciones de desempleo o las crisis matrimoniales (menos del nueve por ciento de los deudores se encontraban libres de

estadounidense, se evidencia la enorme incidencia que las enfermedades y los gastos que de ellas se derivan tienen en las situaciones de sobreendeudamiento de los consumidores. Se ofrecen abundantes datos estadísticos que demuestran que casi un $50 \%$ de las crisis económicas tienen que ver con problemas de salud.

55 Sabella, M.A.: «The category 5 crisis: how hurricanes Katrina and Rita exposed deficiencies in the bankruptcy abuse prevention and consumer protection act of 2005», American Bankruptcy Law Journal, núm. 15 (2007), pp. 321-358, evidencia, a la luz de la crisis originada por los huracanes que asolaron el Golfo de México, la irracionalidad que supone exigir, sin percartarse de las excepcionales circunstancias, la presentación de documentos de cara a la superación del «means test», o la obligación de someterse a «credit counseling» o de cursar programas de educación en materia de gestión de gastos, cuando la crisis económica no se debe, en ningún caso, a errores cometidos por el deudor. Asimismo subraya que el aumento de las tarifas cobradas por los letrados a consecuencia de su nuevo régimen de responsibilidad contribuye también a dificultar el acceso al «fresh start» de las víctimas del desastre.

56 Schlecter, D.: «Before and after the bankruptcy abuse prevention and consumer protection act of 2005 examined under recent case law: a curse in disguise for consumers?», Whittier Law Review, núm. 27, pp. 787-831, comenta varios «case law» en los que ya se evidencian los resultados perversos apuntados. Al respecto, ver nota 53, que evidencia como la ambigüedad en determinados conceptos coadyuva a generar este tipo de situaciones. 
estas contingencias). Todos estos datos, sumados a que una gran parte de los deudores se ven acuciados, además, por obligaciones hipotecarias, parecen avalar las tesis de los críticos con la reforma, que aseguraban, como ahora parece confirmarse, que el porcentaje de "abuso» en las solicitudes era mínimo ${ }^{57}$ y no justificaba, en ningún caso, la promulgación de una norma que encontraba su sentido precisamente en la supuesta generalización de esa práctica ${ }^{58}$.

De igual forma, la mayoría de los deudores supera el «means test», lo que vuelve a evidenciar que no había un «remanente» de ingresos que se malograse con la liquidación operada en el Capítulo 7. En consecuencia, la pretendida redistribución entre los procedimientos del Capítulo 7 y los del Capítulo 13 es apenas significativa ${ }^{59}$, lo que, sumado a la disminución global de solicitudes, no parece secundar la inicial perspectiva de los impulsores de la reforma, que esperaban que los acreedores «recuperasen» fondos gracias a la entrada en vigor de la norma. Quienes sí han aumentado los ingresos son los letrados, a consecuencia del agravamiento de su responsabilidad, y las agencias encargadas de prestar servicios obligatorios de asesoramiento, a costa, obviamente, de un sensible encarecimiento del proceso para los consumidores ${ }^{60}$.

57 Los datos resultan, en ocasiones, muy contundentes: en estudios estadísticos recientes se evidencia como un $45 \%$ de los consumidores que intentan acogerse al «fresh start» hubieron de cancelar una visita médica necesaria a consecuencia de sus problemas económicos, como más del $25 \%$ sufrieron cortes de suministros básicos, y como, finalmente, casi un $20 \%$ tuvieron serias dificultades a la hora de adquirir alimentos. Ver Himmelstein, D.U.; Warren, E.; Thorne, D. y Woolhandler, S.: en Health Affairs (2 de febrero de 2005).

58 Ver completo estudio estadístico en http://www.uscourts.gov/bnkrpctystats/ statistics.htm y en http://www.bankruptcyaction.com/USbankstats.htm (incluye un significativo perfil del consumidor sobreendeudado medio).

59 A pesar de que, en términos relativos, se ha producido un incremento de un $10 \%$ en las solicitudes del Capítulo 13 (ver nota 15), atendiendo a cifras absolutas tales procedimientos pasan de 409.000 en 2005 a 250.000 en 2006, por lo que hay que concluir que, por lo menos hasta el momento, no se ha conseguido el resultado que pretendía BAPCPA a estos efectos. Ver Kassebaum, D.W.: "BAPCPA's effects on consumer bankruptcy filings», Northwestern Financial Review (15-30 de junio de 2007). Disponible íntegramente en http://findarticles.com/p/articles/mi_qa3799/is_20070615/ ai_n19338580.

60 Kassebaum, D.W., en Northwestern Financial Review (15-30 de junio de 2007), aprecia subidas de 209 a 299 dólares en las tasas a pagar al tribunal en los procedimientos del Capítulo 7, mientras que la súbida para el Capítulo 13 es de 150 a 274 dólares; el coste mínimo de atender al «credit counseling» y al curso de educación del consumidor no baja en ningún caso de 150 dólares y, si a todo esto le sumamos el incremento en los honorarios de los letrados, el resultado es un incremento medio de unos 1000 dólares a consecuencia de la reforma. 
Por otro lado, la burocratización excesiva del proceso, en ese afán por dotarlo de múltiples elementos objetivos que eliminen de forma absoluta el margen de discrecionalidad, provoca un alargamiento del mismo que resulta también perjudicial para los intereses, no sólo de los deudores, sino también de los acreedores.

El hecho de que algunos de los cambios propiciados por la S. 256 sean justificados, como la limitación en los plazos para repetir un Capítulo 7 o las restricciones en el cambio de domicilio previo a la solicitud, no es óbice para que los datos evidenciados, que han motivado incluso la temprana aparición de iniciativas legislativas de "contrarreforma», permitan ya realizar una valoración global de la reforma francamente negativa. La experiencia habida hasta la fecha parece contraria a las expectativas que habían generado los defensores de BAPCPA, resultando ésta una reforma que no sólo no cumple con sus principales objetivos sino que, al mismo tiempo, ocasiona problemas estructurales reseñables. A pesar de que la coyuntura económica es la causa principal que ha motivado la crisis del mercado hipotecario en los Estados Unidos ${ }^{61}$ o la sensible recesión en el consumo62, no hay que despreciar la también negativa incidencia de esta reforma, que dificulta el acceso a un sistema, como el del «fresh start», que durante mucho tiempo ejerció de contrapeso de la limitada concepción que del Estado Social se tiene en USA.

61 Aunque parte de la doctrina no considera en absoluto despreciable la influencia que ha tenido la norma ahora analizada en esta singular crisis. Ver, al respecto, Toth-Fejel, A.: «BAPCPA significantly contributed to the Mortgage Crisis, according to Federal Reserve Bank of New York Staff Report», en http://blsbulletins.blogspot.com/2009/01/ bapcpa-significantly-contributed-to.html

62 Ver noticia de El Mundo (27 de diciembre de 2007), p. 35, que comenta la importante recesión en el consumo y que, de alguna manera, parece dar la razón a los 92 profesores de Derecho que, el 16 de febrero de 2005, remitieron una carta a los senadores responsables de la tramitación de BAPCPA, advirtiendo de sus posibles consecuencias negativas, y señalando, a tales efectos, que «the pain will not only be felt by the debtors themselves, but also by the local merchants, whose customers will not have the benefit of the fresh start». 